\section{An ortho-tolidine hydrochloride test for the detection of occult blood in faeces without dietary restrictions}

\author{
NAGI WAHBA From the Biochemistry Depart- \\ ment, Faculty of Medicine, Ein-Shams University, \\ Cairo, Egypt, U.A.R.
}

The most widely used chemical test for occult blood involves the use of benzidine in one form or another. In the last few years it has been necessary to replace benzidine, because of its carcinogenic properties, by o-tolidine. Kohn and O'Kelly $(1952,1955)$ described an o-tolidine method for occult blood, but the patients must be on a meat-free diet or a very large number of false positive results will be obtained. Smith (1958) used more dilute solutions of o-tolidine for patients who are on a normal diet, but the test is much less sensitive than the standard o-tolidine test.

Caplan and Discombe (1951) reported that o-tolidine hydrochloride (solid) is the most sensitive of all the chemical tests for blood in urine and rarely gives false positives. O-tolidine hydrochloride has the advantages over the o-tolidine base in that it can be used in aqueous solution and that solution is more stable. The o-tolidine hydrochloride method described below is standardized to find a level of sensitivity such that negative results are obtained from patients who are not bleeding into the gastrointestinal tract and are on a normal diet. This method has been in routine use in this laboratory for two years and has been found to be very satisfactory.

\section{REAGENTS}

STOCK SOLUTION This is $3 \%$ o-tolidine hydrochloride in water. Do not use heat in preparing the solution and keep in brown bottles in a refrigerator at $4^{\circ} \mathrm{C}$.

Received for publication 8 January 1965.
WORKING SOLUTION This is $1 \%$ o-tolidine hydrochloride ( $33 \%$ dilution). Mix equal parts of stock solution, glacial acetic acid, and ethanol. Store at $4^{\circ} \mathrm{C}$ in a refrigerator and renew monthly.

\section{VOLUME HYDROGEN PEROXIDE}

\section{TECHNIQUE}

FAECES Into a perfectly clean small tube or in one of the cavities of a white cavity porcelain tile, measure accurately four drops of the appropriate working solution and one drop of $\mathbf{2 0}$ volume hydrogen peroxide. Allow to stand for one minute to ensure that there is no contamination of tube or tile or reagent. If no blue or green colour develops, add one drop of the faecal suspension. The appearance of a green or blue colour within five seconds to two minutes indicates the presence of blood; the colour lasts from 30 minutes to several hours, depending upon the intensity of the reaction.

SENSITIVITY OF THE METHOD Various dilutions of blood in faecal suspension from normal subjects on a normal diet were tested with three dilutions of each of the o-tolidine reagent (Smith, 1958) and the o-tolidine hydrochloride reagent and the results obtained are shown in Table I.

OCCULT BLOOD TESTS ON HOSPITAL IN-PATIENTS Three specimens of faeces were collected from each of 35 selected hospital in-patients (20 males and 15 females; ranged from 20 to 60 years) on a normal hospital diet (excluding liver) who had no signs or symptoms of gastrointestinal or other disease which might cause bleeding into the alimentary tract. Each specimen was tested for occult blood, and the results are shown in Table II.

URINE One drop of the sediment of $10 \mathrm{ml}$. centrifuged urine is used instead of 1 drop of the faecal suspension. Various dilutions of blood in urine were tested and the results obtained are shown in Table III.

Ordinary urine specimens from 100 patients ( 70 males and 30 females of different ages) without known haematuria were tested and five gave positive results. In every case further investigation showed a pathological cause.

TABLE I

SENSITIVITY OF DIFFERENT TESTS

Dilution of Blood in Faeces
White Tile or Tube Test

Dilution of O-tolidine
Hydrochloride Stock Solution

1 in $3 \quad 1$ in $5 \quad 1$ in 20

Dilution of O-tolidine Base Stock Solution

1 in $3 \quad 1$ in $5 \quad 1$ in 20

Tablet Tests

O-tolidine O-tolidine Base Hydrochloride 
TABLE II

OCCULT BLOOD TESTS ON HOSPITAL PATIENTS

Result of Test Dilution of O-tolidine Hydrochloride Stock Solution

Dilution of O-tolidine Base Stock Solution

Negative $(-)$
Weakly positive $(+)$
Positive $(++)$
Strongly positive $(+++)$

1 in 3
$97 \%$
$1 \%$
$1 \%$
$1 \%$

$\begin{array}{ll}1 \text { in } 5 & 1 \\ 2 \% & 1 \\ - & -\end{array}$

$\begin{array}{ll}1 \text { in } 20 & 1 \text { in } \\ 100 \% & 3 \% \\ - & 50 \% \\ - & 32 \%\end{array}$

\begin{tabular}{llc}
\hline 1 in 3 & 1 in 5 & 1 in 20 \\
$3 \%$ & $25 \%$ & $85 \%$ \\
$5 \%$ & $25 \%$ & $7 \%$ \\
$60 \%$ & $47 \%$ & $6 \%$ \\
$32 \%$ & $3 \%$ & $2 \%$
\end{tabular}

TABLE III

SENSITIVITY OF THE TEST TO DILUTIONS OF BLOOD IN URINE

Dilution of Blood in Urine Dilution of O-tolidine Hydrochloride Stock Solution

Dilution of O-tolidine Base Stock Solution

\begin{tabular}{|c|c|c|c|c|c|c|}
\hline & & \\
\hline & 1 in 3 & 1 in 5 & 1 in 20 & 1 in 3 & 1 in 5 & 1 in 20 \\
\hline $\begin{array}{ll}1 & : 1,000,000 \\
1 & : 100,000 \\
1 & : 10,000 \\
1 & : 1,000\end{array}$ & $\begin{array}{l}- \\
+ \\
++ \\
+++\end{array}$ & $\begin{array}{l}- \\
\bar{t} \\
+++\end{array}$ & $\begin{array}{l}- \\
- \\
+ \\
++\end{array}$ & $\begin{array}{l}- \\
++ \\
+++ \\
+++\end{array}$ & $\begin{array}{l}- \\
- \\
++ \\
++t\end{array}$ & $\begin{array}{l}- \\
\overline{+} \\
++\end{array}$ \\
\hline
\end{tabular}

TABLET TESTS Tests using tablets similar to those of REFERENCES Watson-Williams (1955), replacing o-tolidine by o-tolidine hydrochloride following the technique of Smith (1958), were done and the results obtained are also shown in Table I. Kohn, J., and O'Kelly, T. (1952). Ibid., 2, 1308.

- (1955). J. clin. Path., 8, 249.

Smith, R. L. (1958). Brit. med. J., 1, 1336.

Watson-Williams, E. J. (1955). Ibid., 1, 1511. 